\title{
The Contribution of Interleukin-12 Genetic Variations to Taiwanese Lung Cancer
}

\author{
MENG-FENG WU ${ }^{1,2,3^{*}}$, YUN-CHI WANG ${ }^{1 *}$, HSIN-TING LI ${ }^{1,4^{*}}$, WEI-CHUN CHEN ${ }^{1,5,6}$, CHENG-HSI LIAO ${ }^{1}$, \\ TZU-CHING SHIH ${ }^{4}$, WEN-SHIN CHANG ${ }^{1}$, CHIA-WEN TSAI $^{1}$, TE-CHUN HSIA ${ }^{1,5,6}$ and DA-TIAN BAU ${ }^{1,7,8}$ \\ ${ }^{1}$ Terry Fox Cancer Research Laboratory, Translational Medicine Research Center, \\ China Medical University Hospital, Taichung, Taiwan, R.O.C.; \\ ${ }^{2}$ Division of Chest Surgery, Department of Surgery, \\ Taoyuan Armed Forces General Hospital, Taoyuan, Taiwan, R.O.C.; \\ ${ }^{3}$ National Defense Medical Center, Taipei, Taiwan, R.O.C.; \\ ${ }^{4}$ Department of Biomedical Imaging and Radiological Science, \\ China Medical University, Taichung, Taiwan, R.O.C.; \\ ${ }^{5}$ Department of Respiratory Therapy, China Medical University, Taichung, Taiwan, R.O.C.; \\ ${ }^{6}$ Division of Pulmonary and Critical Care Medicine, Department of Internal Medicine, \\ China Medical University Hospital, Taichung, Taiwan, R.O.C.; \\ ${ }^{7}$ Graduate Institute of Biomedical Sciences, China Medical University, Taichung, Taiwan, R.O.C.; \\ ${ }^{8}$ Department of Bioinformatics and Medical Engineering, Asia University, Taichung, Taiwan, R.O.C.
}

\begin{abstract}
Background/Aim: Lung cancer is the leading cause of cancer-related death and a better marker for advanced personalized therapeutic approaches, such as immunotherapies, is in urgent need. Interleukin-12 (IL-12) is a cytokine that has been reported to exhibit potent tumoricidal effects, however, the contribution of IL-12 genotypes to lung cancer is still largely unrevealed. The aim of this study was to investigate whether single nucleotide polymorphisms (SNPS) in IL-12A and $I L-12 B$ are associated with lung cancer in a Taiwanese population. Materials and Methods: Genotypes of 358 lung cancer patients and 716 controls were determined by the polymerase chain reaction-restriction fragment length polymorphism method. Results: The distributions of genotypic $(p=0.0036)$ and allelic $(p=0.0005)$ frequencies of $I L-12 \mathrm{~A}$ rs568408 demonstrated significant differences between cases and controls. In detail, the AA genotype of IL-12A rs568408 was associated with a significantly elevated risk of lung cancer
\end{abstract}

*These Authors contributed equally to this study.

Correspondence to: Da-Tian Bau, Te-Chun Hsia and Chia-Wen Tsai, Terry Fox Cancer Research Laboratory, Translational Medicine Research Center, China Medical University Hospital, 2 Yuh-Der Road, Taichung, 404 Taiwan, R.O.C. Tel: +886 422053366 (Ext. 5805), e-mail: datian@mail.cmuh.org.tw; artbau2@gmail.com

Key Words: Genotype, interleukin-12, lung cancer, single nucleotide polymorphism, Taiwan. compared with the GG genotype (odds ratio $(O R)=2.41,95 \%$ confidence interval $(C I)=1.36-4.29, p=0.0021)$. No difference was observed regarding IL-12A rs2243115 and IL-12B rs3212227 genotypes between the case and control groups. In addition, the results of interaction analysis showed that the $A A$ genotype of IL-12A rs568408 was associated with elevated lung cancer risk, especially among those with smoking habits ( $p=0.0043)$. Conclusion: IL-12A rs568404 AA genotype may contribute to the etiology and serve as a genomic determinant of lung cancer in Taiwanese, especially smokers.

Lung cancer remains a serious public health problem since it has been the leading cause of cancer mortality worldwide $(1,2)$. Although the first-line chemotherapeutic approaches such as paclitaxel (PTX) and cisplatin (CDDP) doublet chemotherapy are effective for non-small cell lung cancer (NSCLC) and small cell lung cancer (SCLC) (3-5), the 5 -year survival rate is still very low (6-8). Thus, a better target or marker for advanced personalized therapeutic approaches such as immunotherapies are in urgent need. To fulfill this aim, mounting studies have reported that specific genotypes are associated with increased lung cancer risk for cigarette smokers relative to non-smokers (9-16) and vice versa (17-20). These studies elucidating the contribution of both genomic and behavioral factors to lung cancer etiology may provide the basis for better therapeutic decisions.

Interleukin 12 (IL-12) is a cytokine originally identified as a natural killer (NK) cell stimulatory factor (NKSF) and a cytotoxic lymphocyte maturation factor $(21,22)$. IL-12 has 
been reported to stimulate $\mathrm{NK}$ and $\mathrm{T}$ cell proliferation, enhance their cytolytic activity and induce cytokine production, particularly IFN- $\gamma(23,24)$. Also, IL-12 plays an important role in bridging innate and adaptive immunity by promoting the differentiation of T helper 1 (TH1) cells (25, 26). IL-12 has the potential of antitumor capacity since mice lacking IL-12 subunit p35 develop earlier and higher numbers of papilloma compared to the wild-type mice (27). It has also been shown that the growth of B16 melanomas is faster in mice that are deficient in IL-12 receptor chain IL$12 \mathrm{R} \beta 2$ compared to wild-type mice (28). In mice tumor models, exogenous administration of IL-12 exhibited antitumor effects against the growth of various types of cancer including sarcoma, melanoma, lung carcinoma and breast carcinoma (29-31). Clinically, although IL-12 has certain side-effects, its curative effect is impressive and significant. The results from IL-12 phase I/II trials in patients with Bcell lymphoma or Kaposi sarcoma were very successful and promising for future clinical practice $(32,33)$. Combined with IL-18, IL-12 treatment can restore the intratumoral NK cell functions in MHC (major histocompatibility complex) class I-deficient tumors $(34,35)$. In 2016, it was reported that IL-12 inhibited tumor angiogenesis with the help of interferon- $\gamma$ produced by natural killer cells (36).

Human $I L-12 A$ and $I L 12 B$ genes are located at chromosome 3 and 5, respectively. Among the SNPs of $I L-12, I L-12 A$ rs568408, $I L-12 B$ rs2243115 and $I L-12 B$ rs3212227 are the three polymorphic sites most examined. $I L-12 A$ rs568408 and $I L-12 B$ rs3212227, located in the 3'-untranslated region (3'UTR), may disrupt exonic splicing and influence the production level of IL-12 (37, 38). IL-12A rs2243115 is situated in the 5'UTR, and its functional significance has not been well examined or conclusively reported. As for the contribution of IL-12A and IL-12B to lung cancer, TT genotype at $I L-12 A$ rs662959 was found to be associated with higher risk of cancer progression in NSCLC patients (39). However, the effects of $I L-12 A$ rs662959 TT genotype on the expression level of IL-12 has not yet revealed. In the current study, the contribution of $I L-12 A$ and $I L-12 B$ genotypes to the risk of lung cancer, as well as the interaction of $I L-12$ genotypes and smoking were investigated Taiwanese patients.

\section{Materials and Methods}

Investigated population. Three hundred and fifty-eight patients diagnosed with lung cancer were recruited by the surgery team at the Outpatient Clinics of General Surgery at the China Medical University Hospital during 2005-2008. The clinical characteristics of patients, including histological details, were all graded and defined by expert surgeons. The patients with history of any other cancer and pulmonary diseases, such as chronic obstructive pulmonary disease (COPD), pneumothorax and asthma, were excluded from the databank. All participants were Taiwanese and voluntarily completed a self-administered questionnaire and provided their blood sample for genotyping studies. At the same time, twice as many non-lung cancer healthy volunteers as controls matched for age, gender and smoking behavior were selected after initial random sampling from the Health Examination Cohort of China Medical University Hospital. The exclusion criteria of the controls included previous malignancy, metastasized cancer from other or unknown origin and any genetic or familial diseases. The study was approved by the Institutional Review Board of the China Medical University Hospital with the document coded DMR100-IRB-284 and written informed consent was obtained from all participants. Selected, characteristics of all the investigated subjects are summarized in Table I.

IL-12 polymerase chain reaction-restriction fragment length polymorphism genotyping conditions. Genomic DNA from peripheral blood leucocytes was prepared using the QIAamp Blood Mini Kit (Blossom, Taipei, Taiwan) $(40,41)$ and further processed in typical polymerase chain reactions (PCR) as we have previously described (42-44). The primer sequences for $I L-12$ genotyping were those designed by Chen and his colleagues (37). For $I L-12 \mathrm{~A}$ rs2243115 and rs568408, the forward primers were introduced a mismatched $\mathrm{A}$ to replace $\mathrm{C}$ and a mismatched $\mathrm{T}$ to replace $\mathrm{C}$, respectively, at -3 bp from the polymorphic sites to create Bsen I and Nde I (New England BioLabs, Ipswich, MA, USA) digestible restriction sites. For IL-12A rs568408, the primers were 5'AGAAAAGACCTGTGAACAAAACGACT-3' (forward) and 5'AGATGGCTCACTAGATGCCAGG-3' (reverse). For IL-12A rs2243115, the primers were 5'-GAAGGATGGGACYAT TACATCCATAT-3' (forward) and 5'-CAGGATGGATATTTTCC CTTCT-3' (reverse). The wild-type allele of $I L-12 A$ rs $2243115 T$ generated a fragment of $122 \mathrm{bp}$ while the variant allele $I L-12 \mathrm{~A}$ rs2243115G produced two fragments of 93 and $29 \mathrm{bp}$ after PCR and digestion. As for $I L-12 A$ rs568408, the wild-type allele $I L-12 A$ rs568408G produced 2 fragments of 98 and $23 \mathrm{bp}$ and the variant allele $I L-12 A$ rs568408A resulted in a fragment of $121 \mathrm{bp}$. The primers for $I L-12 B$ rs3212227 were 5'-GATATCTTTGCTGTATT TGTATAGTT-3' (forward) and 5'-AATATTTAAATAGCATG AAGGC-3' (reverse). The PCR that included these primers generated a 118-bp fragment which was then digested by Taq I (New England BioLabs, Ipswich, MA, USA). The variant allele $I L-12 B$ rs3212227C produced 2 fragments of 92 and $26 \mathrm{bp}$, and the wild-type allele $I L$ $12 B$ rs3212227A a single 118-bp fragment.

The PCR cycling were set as: one cycle at $94^{\circ} \mathrm{C}$ for $5 \mathrm{~min} ; 35$ cycles of $94^{\circ} \mathrm{C}$ for $30 \mathrm{sec}, 55^{\circ} \mathrm{C}$ for $30 \mathrm{sec}$, and $72^{\circ} \mathrm{C}$ for $30 \mathrm{sec}$; and a final extension at $72^{\circ} \mathrm{C}$ for $10 \mathrm{~min}$. The PCR and digestion fragments were analyzed in a $3 \%$ agarose gel. The genotype analysis was performed by three researchers independently and blindly. For each $I L-12 \mathrm{SNP}$, five percent of the PCR products were randomly selected for direct sequencing and the results from PCRRFLP and direct sequencing were $100 \%$ concordant.

Statistical analyses. Seven hundred and sixteen of the controls and 358 lung cancer patients were included in the analysis. The Student's $t$-test was used to compare the difference of age between case and control groups. Pearson's Chi-square test was used to compare the distribution of $I L-12$ genotypes between the lung cancer and control groups. The associations between the $I L-12$ genotypes and lung cancer risk were estimated by computing odds ratios (ORs) and their 95\% confidence intervals (CIs) from logistic regression analysis. Any comparison with $p<0.05$ was considered as statistically significant. 
Wu et al: $I L-12$ Genotypes in Taiwanese Lung Cancer Patients

Table I. Distribution of selected demographic data of the 358 patients with lung cancer and the 716 matched controls.

\begin{tabular}{|c|c|c|c|c|c|c|c|}
\hline \multirow[t]{2}{*}{ Characteristics } & \multicolumn{3}{|c|}{ Controls $(\mathrm{n}=716)$} & \multicolumn{3}{|c|}{ Patients $(\mathrm{n}=358)$} & \multirow[t]{2}{*}{$p$-Value ${ }^{\mathrm{a}}$} \\
\hline & $\mathrm{n}$ & $\%$ & Mean (SD) & $\mathrm{n}$ & $\%$ & Mean (SD) & \\
\hline Age (years) & & & $64.8(6.8)$ & & & $64.0(6.9)$ & 0.5871 \\
\hline \multicolumn{8}{|l|}{ Gender } \\
\hline Male & 488 & $68.1 \%$ & & 254 & $70.9 \%$ & & \\
\hline Female & 228 & $31.9 \%$ & & 104 & $29.1 \%$ & & 0.3642 \\
\hline \multicolumn{8}{|l|}{ Smoking status } \\
\hline Ever smokers & 563 & $78.6 \%$ & & 293 & $81.8 \%$ & & \\
\hline Non-smokers & 153 & $21.4 \%$ & & 65 & $18.2 \%$ & & 0.2282 \\
\hline \multicolumn{8}{|l|}{ Histology } \\
\hline Adenocarcinoma & & & & 218 & $60.9 \%$ & & \\
\hline SCC & & & & 106 & $29.6 \%$ & & \\
\hline Other & & & & 34 & $9.5 \%$ & & \\
\hline
\end{tabular}

aBased on Chi-square test; SCC: squamous cell carcinoma; SD: standard deviation.

Table II. Distribution of IL-12A rs568408, IL-12A rs2243115 and IL-12B rs3212227 genotypes among the 358 lung cancer patients and the 716 controls.

\begin{tabular}{|c|c|c|c|c|c|c|}
\hline \multirow[t]{2}{*}{ Genotype } & \multicolumn{2}{|c|}{ Cases } & \multicolumn{2}{|c|}{ Controls } & \multirow[t]{2}{*}{ OR (95\%CI) } & \multirow[t]{2}{*}{$p$-Value ${ }^{a}$} \\
\hline & $\mathrm{n}$ & $\%$ & $\mathrm{n}$ & $\%$ & & \\
\hline \multicolumn{7}{|l|}{$I L-12 A$} \\
\hline \multicolumn{7}{|l|}{ rs568408 } \\
\hline GG & 242 & $67.6 \%$ & 539 & $75.3 \%$ & 1.00 (reference) & \\
\hline $\mathrm{AG}$ & 90 & $25.1 \%$ & 153 & $21.4 \%$ & $1.31(0.97-1.77)$ & 0.0784 \\
\hline AA & 26 & $7.3 \%$ & 24 & $3.3 \%$ & $2.41(1.36-4.29)$ & $0.0021 *$ \\
\hline $\mathrm{AG}+\mathrm{AA}$ & 116 & $32.4 \%$ & 177 & $24.7 \%$ & $1.46(1.10-1.93)$ & $0.0077 *$ \\
\hline $\begin{array}{c}P_{\text {trend }} \\
I L-12 A\end{array}$ & & & & & & $0.0036 *$ \\
\hline \multicolumn{7}{|l|}{ rs 2243115} \\
\hline TT & 310 & $86.6 \%$ & 609 & $85.1 \%$ & 1.00 (reference) & \\
\hline TG & 33 & $9.2 \%$ & 78 & $10.9 \%$ & $0.83(0.54-1.28)$ & 0.3980 \\
\hline GG & 15 & $4.2 \%$ & 29 & $4.0 \%$ & $1.01(0.54-1.92)$ & 0.9608 \\
\hline $\mathrm{TG}+\mathrm{GG}$ & 48 & $13.6 \%$ & 107 & $14.9 \%$ & $0.88(0.61-1.27)$ & 0.4994 \\
\hline $\begin{array}{r}P_{\text {trend }} \\
I L-12 B\end{array}$ & & & & & & 0.6956 \\
\hline \multicolumn{7}{|l|}{ rs 3212227} \\
\hline AA & 136 & $38.0 \%$ & 258 & $36.0 \%$ & 1.00 (reference) & \\
\hline $\mathrm{AC}$ & 140 & $39.1 \%$ & 297 & $41.5 \%$ & $0.89(0.67-1.19)$ & 0.4483 \\
\hline $\mathrm{CC}$ & 82 & $22.9 \%$ & 161 & $22.5 \%$ & $0.97(0.69-1.35)$ & 0.8417 \\
\hline $\mathrm{AC}+\mathrm{CC}$ & 222 & $62.0 \%$ & 458 & $64.0 \%$ & $0.92(0.71-1.20)$ & 0.5308 \\
\hline$P_{\text {trend }}$ & & & & & & 0.7416 \\
\hline
\end{tabular}

aBased on Chi-square without Yate's correction test; the significant $p$-value and odds ratio are bolded and marked with a star.

\section{Results}

The distributions of age and gender for the investigated 358 lung cancer patients and the 716 matched controls are summarized in Table I. As all the controls and cases were matched by age, gender and smoking behavior, there were no differences between the two groups in these aspects ( $p=0.5871$ and 0.3642 , respectively) (Table I). The nonsmoker percentages in the lung cancer patients and matched controls were $18.2 \%$ and $21.4 \%$, respectively $(p=0.2282)$.

The distribution of genotypic frequencies of the 3 SNPs (rs2243115 and rs568408 in $I L-12 A$ and rs3212227 in $I L$ - 
Table III. Distributions of IL-12A rs568408, IL-12A rs2243115 and IL-12B rs3212227 allelic frequencies among the 358 lung cancer patients and the 716 controls.

\begin{tabular}{|c|c|c|c|c|c|c|}
\hline Allele & Cases & $\%$ & Controls & $\%$ & OR $(95 \% \mathrm{CI})$ & $p$-Value ${ }^{\mathrm{a}}$ \\
\hline \multicolumn{7}{|l|}{$I L-12 A$} \\
\hline \multicolumn{7}{|l|}{ rs568408 } \\
\hline Allele G & 574 & $80.2 \%$ & 1231 & $86.0 \%$ & 1.00 (reference) & \\
\hline Allele A & 142 & $19.8 \%$ & 201 & $14.0 \%$ & $1.52(1.20-1.92) *$ & $0.0005 *$ \\
\hline \multicolumn{7}{|l|}{$I L-12 A$} \\
\hline \multicolumn{7}{|l|}{ rs2243115 } \\
\hline Allele T & 653 & $91.2 \%$ & 1296 & $90.5 \%$ & 1.00 (reference) & \\
\hline Allele G & 63 & $8.8 \%$ & 136 & $9.5 \%$ & $0.92(0.67-1.26)$ & 0.5987 \\
\hline \multicolumn{7}{|l|}{$I L-12 B$} \\
\hline \multicolumn{7}{|l|}{ rs3212227 } \\
\hline Allele A & 412 & $57.5 \%$ & 813 & $56.8 \%$ & 1.00 (reference) & \\
\hline Allele C & 304 & $42.5 \%$ & 619 & $43.2 \%$ & $0.97(0.81-1.16)$ & 0.7346 \\
\hline
\end{tabular}

aBased on Chi-square without Yate's correction test; the significant $p$-value and odds ratio are bolded and marked with a star.

$12 B)$ for all the investigated subjects are summarized in Table II. The genotypic frequencies for the three SNPs agreed with the Hardy-Weinberg equilibrium in each group. Interestingly, there was a significant difference in the distribution of $I L-12 A$ rs568408 genotypes between lung cancer and control groups ( $\mathrm{p}$ for trend=0.0036), but not for those of $I L-12 A$ rs2243115 or $I L-12 B$ rs3212227 (p for trend $>0.05$ ). In detail, the frequencies of the heterozygous variant AG and homozygous variant GG of $I L-12 A$ rs568408 were 25.1 and $7.3 \%$ in the lung cancer group and a little lower (21.4 and $3.3 \%)$ in the control group. The AA $(\mathrm{OR}=2.41$, $95 \% \mathrm{CI}=1.36-4.29, p=0.0021)$ but not the $\mathrm{AG}(\mathrm{OR}=1.31$, $95 \% \mathrm{CI}=0.97-1.77, p=0.0784)$ genotype at IL-12A rs568408 seemed to be a potential biomarker for lung cancer among the Taiwanese. The fact that the combined variant AG+AA at $I L-12 A$ rs568408 also elevated the risk of lung cancer among Taiwanese compared to wild-type GG genotype validated the importance of AA genotype ( $\mathrm{OR}=1.46$, 95\% CI=1.10-1.93, $p=0.0077$ ) (Table II, top part).

The distribution of allelic frequencies of rs568408, rs2243115 in $I L-12 A$ and $\operatorname{rs} 3212227$ in $I L-12 B$ are summarized in Table III. Consistent with the findings in Table II, the allele A at $I L-12 A$ rs568408 was associated with an increased risk of lung cancer, compared with allele $G$ $(\mathrm{OR}=1.52,95 \% \mathrm{CI}=1.20-1.92, p=0.0005)$. In detail, the frequencies of the A and $\mathrm{G}$ alleles of $I L-12 A$ rs568408 were 19.8 and $80.2 \%$ among lung cancer patients and 14.0 and $86.0 \%$ among controls (Table III). On the contrary, the variant $\mathrm{G}$ allele of $I L-12 A$ rs 2243115 and the variant $\mathrm{C}$ allele of $I L$ $12 B$ rs3212227 were not associated with significantly altered risk for lung cancer (Table III, middle and bottom parts).

Since smoking behavior may contribute to lung cancer risk, the interaction of the genotype of $I L-12 A$ rs568408 with the age, gender and smoking behavior of the investigated subjects
Table IV. Distribution of IL-12A rs568408 genotypes among the 358 lung cancer patients and the 716 controls after stratification by smoking status.

\begin{tabular}{lrrrr}
\hline Behavior group & \multicolumn{2}{c}{$I L-12 A$ rs568408 genotype } & \\
\cline { 2 - 4 } & GG (\%) & AG (\%) & AA (\%) & $p$-Value \\
\hline Non-smokers & & & & \\
$\quad$ Controls & $112(73.2 \%)$ & $35(22.9 \%)$ & $6(3.9 \%)$ & \\
$\quad$ Cases & $46(70.8 \%)$ & $14(21.5 \%)$ & $5(7.7 \%)$ & 0.5069 \\
Smokers & & & & \\
$\quad$ Controls & $427(75.8 \%)$ & $118(21.0 \%)$ & $18(3.2 \%)$ & \\
$\quad$ Cases & $196(66.9 \%)$ & $76(25.9 \%)$ & $21(7.2 \%)$ & $\mathbf{0 . 0 0 4 3}^{*}$ \\
\hline
\end{tabular}

aBased on Chi-square without Yate's correction test; the significant $p$-value and odds ratio are bolded and marked with a star.

was examined. The joint effects of $I L-12 A$ rs568408 with smoking status are summarized in Table IV. First, lung cancer patients and matched controls were stratified according to their smoking status and ORs were computed. The results showed that ever smokers carrying the homologous AA genotype at $I L$ $12 A$ rs 568408 were of increased risk of lung cancer after adjusted for smoking habits $(p=0.0043)$ (Table IV, bottom part). On the contrary, there was no significantly elevated lung cancer risk for non-smokers with variant AG or AA genotypes at $I L-12 A$ rs568408 (Table IV, top part).

\section{Discussion}

In the current study, the contribution of $I L-12 A$ rs568408, $I L$ $12 A$ rs2243115 and IL12B rs3212227 genotypes to lung cancer risk among Taiwanese was investigated. The examined samples included 358 lung cancer patients and 716 age-, 
gender- and smoking behavior-matched healthy controls (Table I). From the genotyping results it was found that the $I L-12 A$ rs568408 AA genotype, but not the AG or the genotypes of $I L-12 A$ rs2243115 or IL12B rs3212227 (Tables II and III), was a novel genomic biomarker for detection and prediction of lung cancer risk among Taiwanese. It was further found that the AA genotype of $I L-12 A$ rs568408 was associated with elevated lung cancer risk, especially among those with smoking habits (Tables IV). These findings support the idea that potentially functional polymorphisms in $I L-12$ may be involved in the carcinogenesis of lung cancer risk.

Among the three SNPs examined in this study, the genotypephenotype correlation of $I L-12 B$ rs 3212227 was mostly studied but controversial results were reported. First, the $I L-12 B$ rs3212227 AA genotype was reported to associate with higher expression of IL-12 in the serum of type 1 diabetes patients, compared with the AC or the CC genotypes $(45,46)$. On the contrary, peripheral blood mononuclear cells form individuals carrying the CC genotype at $I L-12 B$ rs3212227 secreted significantly higher levels of IL-12 upon stimulation with lipopolysaccharide and purified protein derivatives than those with the $\mathrm{AC}$ or the AA genotypes (47). Interpretation of the results is complicated by evidence suggesting that IL-12A and IL-12B may control the secretion of each other. It has been shown that the presence of the variant genotype $I L-12 B$ rs3212227 correlated with increased IL-12A secretion, but not IL-12B itself (48). Cancer genomic studies have shown that the CC/AC genotypes of $I L-12 B$ rs 3212227 are associated with increased risk of many types of cancer, including esophageal (49), gastric (50), breast $(51)$, bladder $(52)$, cervical $(37,53)$ and osteosarcoma (54), but some controversial findings have also been reported $(38,55-57)$. A meta-analysis has shown that $I L-12 B$ rs3212227 serves as a potential biomarker for cancer risk among Asians, especially for cervical and nasopharyngeal cancer (58). In 2017, a more updated analysis reported that genotypes at $I L-12 B$ rs 3212227 were significantly correlated with overall cancer risk, especially among Asian ethnicities (59). Our results did not show any association between the genotypes of $I L-12 B$ rs3212227 and lung cancer risk (Tables II and III). The inconsistent conclusions may come from different ethics and/or populations investigated, and the genetic background, life-style, environmental exposure and immunostatus were different among the investigated subjects. Regarding $I L-12 A$ rs2243115, Shi and his colleagues failed to detect any significant association between this polymorphism and cancer risk in either the overall or any subgroup analyses in a meta-analysis in 2018 (60), which is consistent with our findings (Tables II and III).

The highlight of the current study is that a practical biomarker, the AA genotype at $I L-12 A$ rs 568408 , for early detection and prediction lung cancer among Taiwanese is proposed (Tables II and III). The elevated risk was also found in several other types of cancer including colorectal (57), cervical (37), esophageal (49) cancer, hepatocellular carcinoma (38) and osteosarcoma (54). In the most updated meta-analysis of $I L-12 A$ rs568408 and cancer, the genotypes at $I L-12 A$ rs 568408 were found to significantly correlate with overall cancer risk, especially among Asian ethnicities (59).

Smoking is a well-known risk factor for lung cancer. Therefore, the interaction of the genotype of $I L-12 A$ rs568408 and cigarette smoking status of the participants was further analyzed. The results showed that the genotypic distribution of the variant genotype of $I L-12 A$ rs568408 was significantly different between lung cancer and control sub-groups who have smoking habits (Table IV). On the contrary, no differential distribution was observed among non-smokers (Table IV). The interaction of the genotype of $I L-12 A$ rs568408 with age, gender and alcohol drinking status was not found to be significant (data not shown). In the current study, the genotypic and phenotypic data are not yet sufficient enough to establish genotype-phenotype correlations among Taiwanese. Further studies are recommended, using cells from patients in addition to commercial lung cancer cell lines, to explore the differential effects of tobacco compounds on cells with different $I L-12 \mathrm{~A}$ rs568408 genotypes.

In conclusion, the study provides evidence that the AA genotype of $I L-12 A$ rs568408 is associated with an increased lung cancer risk among the Taiwanese, especially those with smoking habits.

\section{Conflicts of Interest}

The Authors declare no conflicts of interest regarding this study.

\section{Acknowledgements}

The Authors are grateful to the Tissue-bank of China Medical University Hospital and doctors/nurses working under Prof. Hsia's leadership for their excellent sample collection and technical assistance. The technical assistance of Huai-Mei Hsu and the consultants of statistical analysis Chih-Hsin Muo and Cheng-Li Lin were very helpful in manuscript preparation. This study was supported mainly by the Taiwan Ministry of Science and Technology (MOST 106-2314-B-039-022) to Dr. Hsia and partially by research grants from China Medical University Hospital (DMR-107-170) to Dr. Hsia.

\section{References}

1 Siegel RL, Miller KD and Jemal A: Cancer statistics, 2015. CA Cancer J Clin 65: 5-29, 2015.

2 Torre LA, Bray F, Siegel RL, Ferlay J, Lortet-Tieulent J and Jemal A: Global cancer statistics, 2012. CA Cancer J Clin 65: 87-108, 2015.

3 Dimitroulis J, Rapti A, Stathopoulos GP, Rigatos S, Stathopoulos J, Koutantos J, Athanasiadis A, Tsikritsaki K, Karaindros D, Katis $\mathrm{K}$, Antoniou $\mathrm{D}$, Toumbis $\mathrm{M}$ and Giamboudakis $\mathrm{P}$ : Comparison of cisplatin-paclitaxel combination versus cisplatinetoposide in patients with small-cell lung cancer: a Phase III study. Oncol Rep 20: 879-884, 2008. 
4 Gupta N, Hatoum H and Dy GK: First line treatment of advanced non-small-cell lung cancer - specific focus on albumin bound paclitaxel. Int J Nanomedicine 9: 209-221, 2014.

5 Rossi A, Chiodini P, Sun JM, O’Brien ME, von Plessen C, Barata F, Park K, Popat S, Bergman B, Parente B, Gallo C, Gridelli C, Perrone F and Di Maio M: Six versus fewer planned cycles of first-line platinum-based chemotherapy for non-smallcell lung cancer: a systematic review and meta-analysis of individual patient data. Lancet Oncol 15: 1254-1262, 2014.

6 Li Z, Chen L and Qin Z: Paradoxical roles of IL-4 in tumor immunity. Cell Mol Immunol 6: 415-422, 2009.

7 Liew MS, Sia J, Starmans MH, Tafreshi A, Harris S, Feigen M, White S, Zimet A, Lambin P, Boutros PC, Mitchell P and John T: Comparison of toxicity and outcomes of concurrent radiotherapy with carboplatin/paclitaxel or cisplatin/etoposide in stage III nonsmall cell lung cancer. Cancer Med 2: 916-924, 2013.

8 Spiro SG and Silvestri GA: One hundred years of lung cancer. Am J Respir Crit Care Med 172: 523-529, 2005.

9 Ji YN, Wang Q and Suo LJ: CYP1A1 Ile462Val polymorphism contributes to lung cancer susceptibility among lung squamous carcinoma and smokers: a meta-analysis. PLoS One 7: e43397, 2012.

10 Spitz MR, Gorlov IP, Dong Q, Wu X, Chen W, Chang DW, Etzel CJ, Caporaso NE, Zhao Y, Christiani DC, Brennan P, Albanes D, Shi J, Thun M, Landi MT and Amos CI: Multistage analysis of variants in the inflammation pathway and lung cancer risk in smokers. Cancer Epidemiol Biomarkers Prev 21: 1213-1221, 2012.

11 Hsia TC, Chang WS, Liang SJ, Chen WC, Tu CY, Chen HJ, Yang MD, Tsai CW, Hsu CM, Tsai CH and Bau DT: Interleukin-10 (IL10) promoter genotypes are associated with lung cancer risk in Taiwan males and smokers. Anticancer Res 34: 7039-7044, 2014.

12 Hsia TC, Chang WS, Chen WC, Liang SJ, Tu CY, Chen HJ, Liang JA, Tsai CW, Hsu CM, Tsai CH and Bau DT: Genotype of DNA double-strand break repair gene XRCC7 is associated with lung cancer risk in Taiwan males and smokers. Anticancer Res 34: 7001-7005, 2014.

13 Hsia TC, Tsai CW, Liang SJ, Chang WS, Lin LY, Chen WC, Tu $\mathrm{CY}$, Tsai $\mathrm{CH}$ and Bau DT: Effects of ataxia telangiectasia mutated (ATM) genotypes and smoking habits on lung cancer risk in Taiwan. Anticancer Res 33: 4067-4071, 2013.

14 Chen X, Lu H, Zhao M, Tashiro K, Cassis LA and Daugherty A: Contributions of leukocyte angiotensin-converting enzyme to development of atherosclerosis. Arterioscler Thromb Vasc Biol 33: 2075-2080, 2013.

15 Liu CJ, Hsia TC, Tsai RY, Sun SS, Wang CH, Lin CC, Tsai CW, Huang CY, Hsu CM and Bau DT: The joint effect of hOGG1 single nucleotide polymorphism and smoking habit on lung cancer in Taiwan. Anticancer Res 30: 4141-4145, 2010.

16 Liu CJ, Hsia TC, Wang RF, Tsai CW, Chu CC, Hang LW, Wang $\mathrm{CH}$, Lee HZ, Tsai RY and Bau DT: Interaction of cyclooxygenase 2 genotype and smoking habit in Taiwanese lung cancer patients. Anticancer Res 30: 1195-1199, 2010.

17 Govindan R: Lung cancer in never smokers: a new hot area of research. Lancet Oncol 11: 304-305, 2010.

18 Liu YL, Xu Y, Li F, Chen H and Guo SL: CYP2A6 deletion polymorphism is associated with decreased susceptibility of lung cancer in Asian smokers: a meta-analysis. Tumour Biol 34: 2651-2657, 2013

19 Lo YL, Hsiao CF, Jou YS, Chang GC, Tsai YH, Su WC, Chen KY, Chen YM, Huang MS, Hsieh WS, Chen CJ and Hsiung CA:
Polymorphisms of MLH1 and MSH2 genes and the risk of lung cancer among never smokers. Lung Cancer 72: 280-286, 2011.

$20 \mathrm{Wu}$ X, Wang L, Ye Y, Aakre JA, Pu X, Chang GC, Yang PC, Roth JA, Marks RS, Lippman SM, Chang JY, Lu C, Deschamps C, Su WC, Wang WC, Huang MS, Chang DW, Li Y, Pankratz VS, Minna JD, Hong WK, Hildebrandt MA, Hsiung CA and Yang P: Genome-wide association study of genetic predictors of overall survival for non-small cell lung cancer in never smokers. Cancer Res 73: 4028-4038, 2013.

21 Kobayashi M, Fitz L, Ryan M, Hewick RM, Clark SC, Chan S, Loudon R, Sherman F, Perussia B and Trinchieri G: Identification and purification of natural killer cell stimulatory factor (NKSF), a cytokine with multiple biologic effects on human lymphocytes. J Exp Med 170: 827-845, 1989.

22 Stern AS, Podlaski FJ, Hulmes JD, Pan YC, Quinn PM, Wolitzky AG, Familletti PC, Stremlo DL, Truitt T, Chizzonite R et al: Purification to homogeneity and partial characterization of cytotoxic lymphocyte maturation factor from human B-lymphoblastoid cells. Proc Natl Acad Sci USA 87: 6808-6812, 1990.

23 Trinchieri G: Interleukin-12 and the regulation of innate resistance and adaptive immunity. Nat Rev Immunol 3: 133-146, 2003.

24 Del Vecchio M, Bajetta E, Canova S, Lotze MT, Wesa A, Parmiani $\mathrm{G}$ and Anichini A: Interleukin-12: biological properties and clinical application. Clin Cancer Res 13: 4677-4685, 2007.

25 Macatonia SE, Hsieh CS, Murphy KM and O'Garra A: Dendritic cells and macrophages are required for Th1 development of CD4+ $\mathrm{T}$ cells from alpha beta TCR transgenic mice: IL-12 substitution for macrophages to stimulate IFN-gamma production is IFN-gamma-dependent. Int Immunol 5: 1119-1128, 1993.

26 Germann T, Gately MK, Schoenhaut DS, Lohoff M, Mattner F, Fischer S, Jin SC, Schmitt E and Rude E: Interleukin-12/T cell stimulating factor, a cytokine with multiple effects on $\mathrm{T}$ helper type 1 (Th1) but not on Th2 cells. Eur J Immunol 23: 17621770, 1993.

27 Langowski JL, Zhang X, Wu L, Mattson JD, Chen T, Smith K, Basham B, McClanahan T, Kastelein RA and Oft M: IL-23 promotes tumour incidence and growth. Nature 442: 461-465, 2006.

28 Eisenring M, vom Berg J, Kristiansen G, Saller E and Becher B: IL-12 initiates tumor rejection via lymphoid tissue-inducer cells bearing the natural cytotoxicity receptor NKp46. Nat Immunol 11: 1030-1038, 2010.

29 Le HN, Lee NC, Tsung K and Norton JA: Pre-existing tumorsensitized $\mathrm{T}$ cells are essential for eradication of established tumors by IL-12 and cyclophosphamide plus IL-12. J Immunol 167: 6765-6772, 2001.

30 Brunda MJ, Luistro L, Warrier RR, Wright RB, Hubbard BR, Murphy M, Wolf SF and Gately MK: Antitumor and antimetastatic activity of interleukin 12 against murine tumors. J Exp Med 178: 1223-1230, 1993.

31 Jaime-Ramirez AC, Mundy-Bosse BL, Kondadasula S, Jones NB, Roda JM, Mani A, Parihar R, Karpa V, Papenfuss TL, LaPerle KM, Biller E, Lehman A, Chaudhury AR, Jarjoura D, Burry RW and Carson WE, 3rd: IL-12 enhances the antitumor actions of trastuzumab via NK cell IFN-gamma production. $\mathrm{J}$ Immunol 186: 3401-3409, 2011.

32 Ansell SM, Witzig TE, Kurtin PJ, Sloan JA, Jelinek DF, Howell KG, Markovic SN, Habermann TM, Klee GG, Atherton PJ and Erlichman C: Phase 1 study of interleukin-12 in combination with rituximab in patients with B-cell non-Hodgkin lymphoma. Blood 99: 67-74, 2002. 
33 Little RF, Aleman K, Kumar P, Wyvill KM, Pluda JM, ReadConnole E, Wang V, Pittaluga S, Catanzaro AT, Steinberg SM and Yarchoan R: Phase 2 study of pegylated liposomal doxorubicin in combination with interleukin-12 for AIDS-related Kaposi sarcoma. Blood 110: 4165-4171, 2007.

34 Ardolino M, Azimi CS, Iannello A, Trevino TN, Horan L, Zhang L, Deng W, Ring AM, Fischer S, Garcia KC and Raulet DH: Cytokine therapy reverses NK cell anergy in MHC-deficient tumors. J Clin Invest 124: 4781-4794, 2014.

35 Zitvogel L and Kroemer G: Cytokines reinstate NK cellmediated cancer immunosurveillance. J Clin Invest 124: 46874689, 2014.

36 Yue T, Zheng X, Dou Y, Zheng X, Sun R, Tian Z and Wei H: Interleukin 12 shows a better curative effect on lung cancer than paclitaxel and cisplatin doublet chemotherapy. BMC Cancer 16: 665, 2016

37 Chen X, Han S, Wang S, Zhou X, Zhang M, Dong J, Shi X, Qian N, Wang X, Wei Q, Shen H and Hu Z: Interactions of IL$12 \mathrm{~A}$ and IL-12B polymorphisms on the risk of cervical cancer in Chinese women. Clin Cancer Res 15: 400-405, 2009.

38 Liu L, Xu Y, Liu Z, Chen J, Zhang Y, Zhu J, Liu J, Liu S, Ji G, Shi H, Shen $\mathrm{H}$ and $\mathrm{Hu} Z$ : IL12 polymorphisms, HBV infection and risk of hepatocellular carcinoma in a high-risk Chinese population. Int J Cancer 128: 1692-1696, 2011.

39 Perez-Ramirez C, Canadas-Garre M, Alnatsha A, Molina MA, Robles AI, Villar E, Delgado JR, Faus-Dader MJ and CallejaHernandez MA: Interleukins as new prognostic genetic biomarkers in non-small cell lung cancer. Surg Oncol 26: 278-285, 2017.

40 Chen GL, Shen TC, Chang WS, Tsai CW, Li HT, Chuang CL, Lai YL, Yueh TC, Hsia TC, Wang SC and Bau DT: The contribution of MMP-7 promoter polymorphisms to Taiwan lung cancer susceptibility. Anticancer Res 38: 5671-5677, 2018.

41 Shen TC, Chang WS, Tsai CW, Chao CY, Lin YT, Hsiao CL, Hsu CL, Chen WC, Hsia TC and Bau DT: The contribution of matrix metalloproteinase-1 promoter genotypes in Taiwan lung cancer risk. Anticancer Res 38: 253-257, 2018.

42 Shen TC, Tsai CW, Chang WS, Wang S, Chao CY, Hsiao CL, Chen WC, Hsia TC and Bau DT: Association of interleukin-12A rs568408 with susceptibility to Asthma in Taiwan. Sci Rep 7: 3199, 2017

43 Shih LC, Li CH, Sun KT, Chen LY, Hsu CL, Hung YW, Wu CN, Hsia TC, Shen TC, Chang WS, Shih TC, Tsai CW and Bau DT: Association of matrix metalloproteinase-7 genotypes to the risk of oral cancer in Taiwan. Anticancer Res 38: 2087-2092, 2018.

44 Liao CH, Wu HC, Hu PS, Hsu SW, Shen TC, Hsia TC, Chang WS, Tsai CW and Bau DT: The association of matrix metalloproteinase-1 promoter polymorphisms with prostate cancer in Taiwanese patients. Anticancer Res 38: 3907-3911, 2018.

45 Morahan G, Huang D, Ymer SI, Cancilla MR, Stephen K, Dabadghao P, Werther G, Tait BD, Harrison LC and Colman PG: Linkage disequilibrium of a type 1 diabetes susceptibility locus with a regulatory IL12B allele. Nat Genet 27: 218-221, 2001.

46 Davoodi-Semiromi A, Yang JJ and She JX: IL-12p40 is associated with type 1 diabetes in Caucasian-American families. Diabetes 51: 2334-2336, 2002.

47 Yilmaz V, Yentur SP and Saruhan-Direskeneli G: IL-12 and IL10 polymorphisms and their effects on cytokine production. Cytokine 30: 188-194, 2005.
48 Seegers D, Zwiers A, Strober W, Pena AS and Bouma G: A TaqI polymorphism in the 3'UTR of the IL-12 p40 gene correlates with increased IL-12 secretion. Genes Immun 3: 419-423, 2002.

49 Tao YP, Wang WL, Li SY, Zhang J, Shi QZ, Zhao F and Zhao BS: Associations between polymorphisms in IL-12A, IL-12B, IL-12Rbeta1, IL-27 gene and serum levels of IL-12p40, IL27 p28 with esophageal cancer. J Cancer Res Clin Oncol 138: 1891-1900, 2012.

50 Yin J, Wang X, Wei J, Wang L, Shi Y, Zheng L, Tang W, Ding $\mathrm{G}$, Liu $\mathrm{C}$, Liu R, Chen $\mathrm{S}, \mathrm{Xu} \mathrm{Z}$ and $\mathrm{Gu} \mathrm{H}$ : Interleukin 12B rs3212227 $\mathrm{T}>\mathrm{G}$ polymorphism was associated with an increased risk of gastric cardiac adenocarcinoma in a Chinese population. Dis Esophagus 28: 291-298, 2015.

51 Kaarvatn MH, Vrbanec J, Kulic A, Knezevic J, Petricevic B, Balen S, Vrbanec D and Dembic Z: Single nucleotide polymorphism in the interleukin $12 \mathrm{~B}$ gene is associated with risk for breast cancer development. Scand J Immunol 76: 329-335, 2012.

52 Ebadi N, Jahed M, Mivehchi M, Majidizadeh T, Asgary M and Hosseini SA: Interleukin- 12 and interleukin- 6 gene polymorphisms and risk of bladder cancer in the Iranian population. Asian Pac J Cancer Prev 15: 7869-7873, 2014.

53 Roszak A, Mostowska A, Sowinska A, Lianeri M and Jagodzinski PP: Contribution of IL12A and IL12B polymorphisms to the risk of cervical cancer. Pathol Oncol Res 18: 997-1002, 2012.

54 Wang J, Nong L, Wei Y, Qin S, Zhou Y and Tang Y: Association of interleukin-12 polymorphisms and serum IL-12p40 levels with osteosarcoma risk. DNA Cell Biol 32: 605-610, 2013.

55 Huang ZQ, Wang JL, Pan GG and Wei YS: Association of single nucleotide polymorphisms in IL-12 and IL-27 genes with colorectal cancer risk. Clin Biochem 45: 54-59, 2012.

56 Miteva L, Stanilov N, Deliysky T, Mintchev N and Stanilova S: Association of polymorphisms in regulatory regions of interleukin-12p40 gene and cytokine serum level with colorectal cancer. Cancer Invest 27: 924-931, 2009.

57 Sun R, Jia F, Liang Y, Li L, Bai P, Yuan F, Gao L and Zhang L: Interaction analysis of IL-12A and IL-12B polymorphisms with the risk of colorectal cancer. Tumour Biol 36: 9295-9301, 2015.

58 Zhou L, Yao F, Luan H, Wang Y, Dong X, Zhou W and Wang $\mathrm{Q}$ : Functional polymorphisms in the interleukin-12 gene contribute to cancer risk: evidence from a meta-analysis of 18 case-control studies. Gene 510: 71-77, 2012.

59 Zheng Y, Wang M, Tian T, Liu K, Liu X, Zhai Y, Lin S, Yang P, Li S, Dai Z and Lu J: Role of interleukin-12 gene polymorphisms in the onset risk of cancer: a meta-analysis. Oncotarget 8: 2979529807, 2017.

60 Shi X, Jia Y, Xie X and Li S: Single-nucleotide polymorphisms of the IL-12 gene lead to a higher cancer risk: a meta-analysis based on 22,670 subjects. Genes Genet Syst 92: 173-187, 2018.

Received October 11, 2018

Revised October 23, 2018

Accepted October 24, 2018 